\title{
Skills, Practice Patterns, and Knowledge of Canadian Family Physician Endoscopists
}

Michael R. Kolber, MD, CCFP, MSc; Shelley Ross, PhD

\begin{abstract}
BACKGROUND AND OBJECTIVES: In Canada, few family physicians (FPs) perform endoscopy. Conflicting evidence exists on the quality of endoscopy performed by Canadian FPs, which may be explained by differing skillsets of these endoscopists. The objective of this study was to perform the first exploration of the practice, skills, and knowledge of Canadian FP endoscopists.
\end{abstract}

METHODS: A cross-sectional survey, including direct knowledge test, was used.

RESULTS: Twenty Canadian FP endoscopists completed the survey. Ninety-five percent practice outside urban centres, all perform gastroscopies, and $85 \%$ perform colonoscopies and polypectomies. These endoscopists are performing about 32 procedures per month. They are using split bowel preparations, performing rectal retroflexion, and tattooing advanced lesions, all characteristics of a quality endoscopist or program. Self-identified knowledge gaps identified included caring for patients with inflammatory bowel disease and staging rectal cancer. Direct testing found gaps in describing Barrett's esophagitis and managing anticoagulated patients who require endoscopy.

CONCLUSIONS: Canadian FP endoscopists appear to be providing quality endoscopic exams and should be supported and encouraged to continue to provide care of rural Canadian patients with gastrointestinal concerns. Future training and continuing education events aimed at this group of endoscopists should target identified knowledge gaps.

(Fam Med. 2018;50(3):212-6.)

doi: 10.22454/FamMed.2018.877757

n Canada, endoscopic procedures are performed primarily by gastroenterologists or general surgeons. ${ }^{1} \mathrm{~A}$ few family physicians (FPs) perform endoscopy, primarily in rural communities. ${ }^{2}$ While some studies demonstrate that Canadian FPs perform high quality endoscopies, ${ }^{3,4}$ others claim future colorectal cancer rates are higher when colonoscopies are performed by non-gastroenterologists. ${ }^{5-7}$ As no formal training program in gastrointestinal (GI) medicine for Canadian FPs exists, current FP endoscopists likely have differing skill sets, a fact which may partially explain the discrepancy in quality findings.

In this study, we performed the first exploration of the practice, skills, and knowledge gaps of Canadian FP endoscopists. We compared responses to current quality assurance recommendations in endoscopy. ${ }^{8,9}$ Identified knowledge gaps will guide future training and educational events aimed at these endoscopists.

\section{Methods}

An online survey was designed by the study authors and piloted by two FP endoscopists (Appendix 1 at https://www.stfm.org/Portals/49/ Documents/FMAppendix/Kolber2017-Appendix1.pdf). Recruitment to voluntarily participate in the study occurred primarily at an annual continuing education (CE) event aimed at Canadian FP endoscopists.

The study was approved by the University of Alberta's Health Research Ethics Board.

\section{Results}

After excluding non-FP and international responses, 20 of the 29 (69\%) Canadian FP endoscopists who attended the CE event completed the survey. Ninety-five percent of respondents practice in a rural or regional community, ${ }^{10} 65 \%$ without local surgical backup. Over half practice in communities at least a 2-hour drive from a gastroenterologist (Table 1).

From the University of Alberta Department of Family Medicine, Edmonton, Alberta, Canada. 
Procedures Performed

All 20 FP endoscopists perform gastroscopies, 17 perform colonoscopies and polypectomies. The three that do not perform colonoscopies perform sigmoidoscopies. Thirteen physicians (65\%) reported usually or always giving their own sedation, most commonly with Fentanyl and Midazolam (Versed; Table 1).

These endoscopists estimate performing eight procedures per day or 32 procedures per month. Over half the physicians who perform colonoscopies (10 of 17) report offering average risk screening colonoscopies, and 15 of 17 routinely use split bowel preparations.

\section{Endoscopic Procedural Skills}

Basic Skills: Eighty percent usually or always attempt a rectal retroflexion. Of the colonoscopists, $76 \%$ routinely photograph cecal landmarks, and $94 \%$ are usually or always able to intubate the terminal ileum if needed (Figure 1).

Advanced Skills: One endoscopist routinely performs esophageal and colonic dilations, while none perform esophageal stenting. Two perform PEG tube insertions, while another two routinely use Argon Plasma Coagulation.

Quality Markers in Colonoscopy Of the 17 colonoscopists, 14 (82\%) claimed to know their cecal intubation and perforation rates, while 12
(71\%) and $10(58 \%)$ reported knowing their postpolypectomy bleed or adenoma detection rates, respectively.

\section{Comfort Level With}

Endoscopic Technical Skills and Self-perceived Knowledge

Eighty-five percent report being moderately or very comfortable performing saline lifts prior to polypectomy. However, only $50 \%$ and $15 \%$ describe being comfortable using endoclips for hemostasis or Argon Plasma Coagulation, respectively (Figure 2).

Most respondents felt they had adequate knowledge on the majority of general GI/endoscopic topics, including diagnosing eosinophilic

Table 1: Characteristics and Practice Patterns of Participants $(n=20)$

\begin{tabular}{|c|c|}
\hline Sex & Male $=18(90 \%$ \\
\hline Practice locations* & $\begin{array}{l}\text { Rural=16 }(80 \%) \\
\text { Regional=3(15\%) } \\
\text { Urban=1 }(5 \%)\end{array}$ \\
\hline Endoscopic or gastrointestinal medicine training time & $\begin{array}{l}<3 \text { months }=6(30 \%) \\
3-6 \text { months }=5(25 \%) \\
>6 \text { months }=9(45 \%)\end{array}$ \\
\hline Estimated number of colonoscopies performed in training & $\begin{array}{l}<100=7(35 \%) \\
100-200=6(30 \%) \\
>200=6(30 \%) \\
\text { Unsure }=1(5 \%)\end{array}$ \\
\hline Current endoscopic practice & $\begin{array}{l}\text { Gastroscopy=20 }(100 \%) \\
\text { Colonoscopy=17 }(85 \%) \\
\text { Sigmoidoscopy=14 }(70 \%) \\
\text { PEG tube insertion=2 }(10 \%)\end{array}$ \\
\hline Number of colonoscopies performed in career $(n=17)$ & $\begin{array}{l}<500=2 \\
501-2,000=4 \\
2,001-5,000=8 \\
>5000=3\end{array}$ \\
\hline Perform own sedation & $\begin{array}{l}\text { Never }=1 \\
\text { Sometimes }=6 \\
\text { Usually or Always=13 }\end{array}$ \\
\hline Local surgical back-up & Yes $=6(35 \%)$ \\
\hline Hours drive from closest gastroenterologist & $\begin{array}{l}0-1=4 \\
1-2=5 \\
>2=11\end{array}$ \\
\hline
\end{tabular}

*Practice location definitions from: Beshiri R, Bollman RD, Clemenson H. Definitions of "rural" (pp. 21-601). 2002. Ottawa, Ontario: Statistics Canada, Agriculture Division:

- Rural: the population living in towns and municipalities outside the commuting zone of larger urban centres (ie, outside the commuting zone of centres with population of 10,000 or more).

- $\quad$ Regional: population between 10,000 and 50,000

- Urban: population $>50,000$. 
Figure 1: Procedural Quality Measures of Survey Respondents

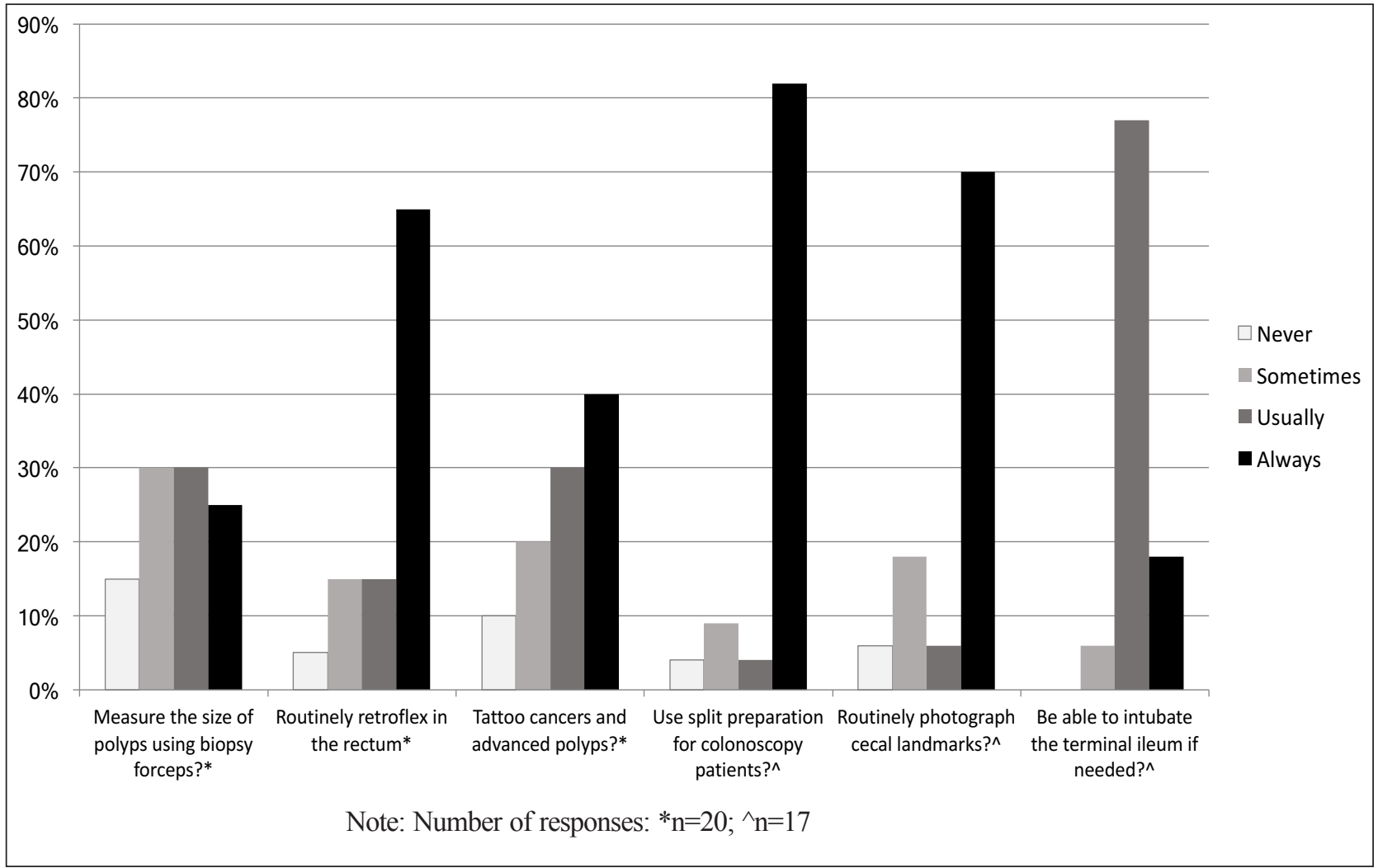

Figure 2: Respondent Comfort With Endoscopy Skills or Clinical Knowledge $(n=20)$

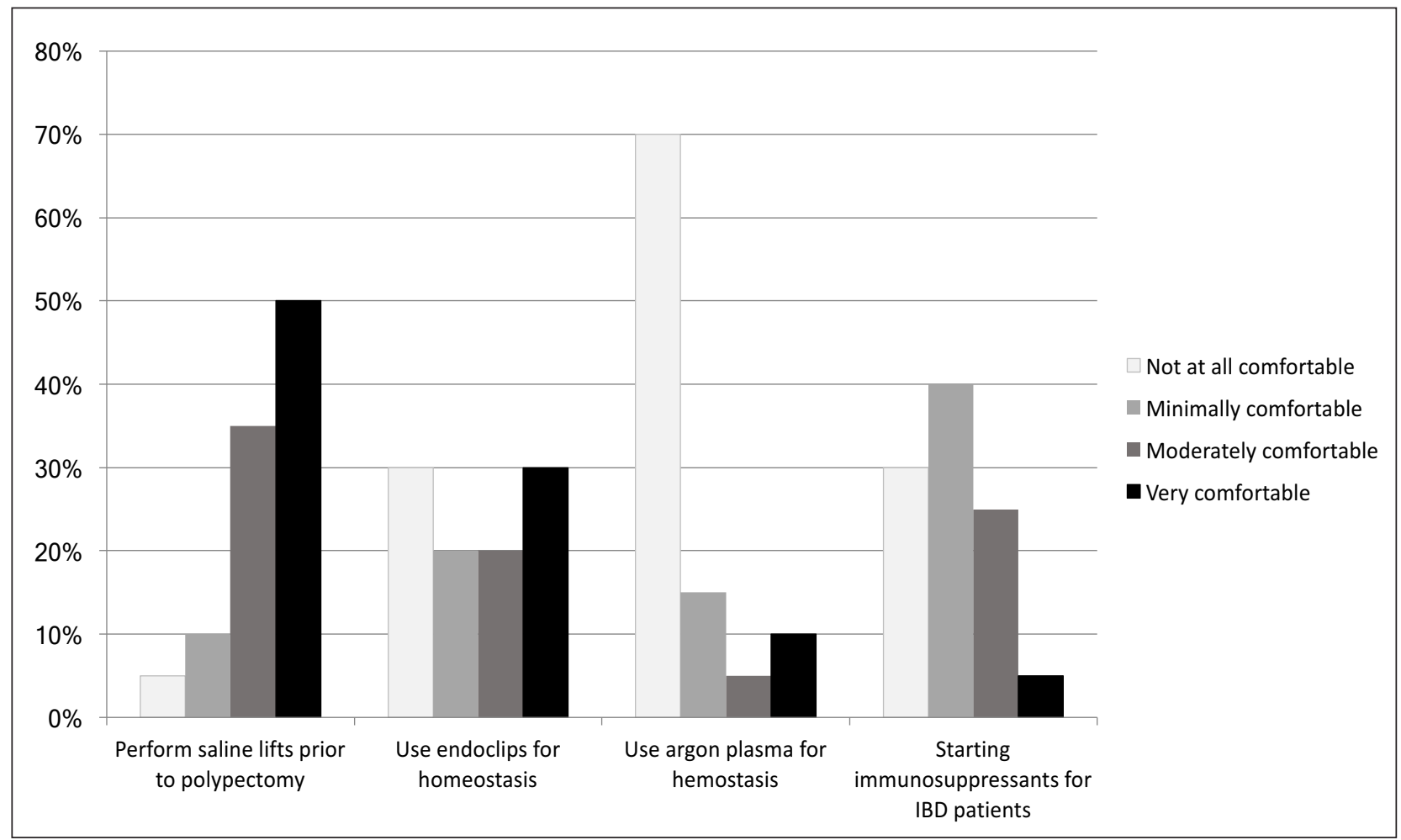


esophagitis, dealing with anticoagulants, or completing the difficult colonoscopy. Self-perceived knowledge gaps identified included starting inflammatory bowel disease patients on immunosuppressants, caring for patients on biologics, as well as the use of (and referring for) endoscopic ultrasound for rectal cancer staging.

\section{Direct Testing of Endoscopic Knowledge}

To test specific knowledge areas, participants were given six multiple choice and one short answer question related to clinical or endoscopic cases (Appendix 1 at https:// www.stfm.org/Portals/49/Documents/ FMAppendix/Kolber-2017-Appendix1.pdf). For a $7 \mathrm{~mm}$ hyperplastic appearing sessile Paris 1s polyp, ${ }^{11} 14$ of 20 of respondents correctly stated they would use a cold snare. ${ }^{8,9}$ For a $1.5 \mathrm{~cm}$ pendunculated adenomatous appearing Paris 1s polyp, 95\% would use a hot snare. ${ }^{9}$ After providing an endoscopic description and landmarks, $28 \%$ were able to correctly use Prague nomenclature to describe a Barrett's esophagitis case. ${ }^{12}$

Without using a decision aid, 37\% of respondents were able to correctly determine a patient's CHADS score (congestive heart failure, hypertension, age $\geq 75$ years, diabetes mellitus, stroke) from a clinical scenario. For the same scenario $(\mathrm{CHADS}=2)$, $63 \%$ correctly recommended stopping the patient's warfarin without bridging. ${ }^{13-15}$ Finally, $89 \%$ correctly recommended stopping the patient's clopidegrol and continuing on aspirin for a routine colonoscopy on a patient with remote cardiac stenting. ${ }^{16,17}$

\section{Discussion}

Our study was the first in-depth analysis of skills, practice patterns, and knowledge of Canadian FPs who perform endoscopy. These endoscopists practice primarily in a rural setting without local general surgery back up. We found performance characteristics adhering to guideline recommendations that could infer quality endoscopy and endoscopic programs including: using split bowel preparations, performing rectal retroflexion, and the ability to intubate the terminal ileum when needed. Advanced procedures, like esophageal dilations or stenting, are being left for other endoscopists to perform. The majority of participating FPs report knowledge of key performance indicators, including cecal intubation and perforation rates, inferring participation in a colonoscopy quality data study or program. As per Global Reporting Systems recommendations, measuring endoscopy outcomes is the first measure in the path towards quality endoscopy. ${ }^{18}$

Self-perceived knowledge gaps, such as caring for the patient with IBD and staging of rectal cancer, were identified. Direct testing identified gaps in describing Barrett's esophagitis and managing patients on anticoagulants who require endoscopy. Expecting endoscopists to correctly describe a Barrett's lesion may highlight that only a minority of endoscopists use the Prague classification. ${ }^{19} \mathrm{~A}$ more clinically meaningful question may have been to determine the ability to recognize, manage, and surveil a patient with Barrett's esophagus. Other studies have found discrepancies in gastroenterologists' care of patients on anticoagulants or antiplatelets who require endoscopy. ${ }^{20-22}$ Recent publications clarifying who requires bridging for endoscopy ${ }^{23}$ and suggesting length of treatment of dual antiplatelet therapy after cardiac events ${ }^{23}$ should help improve the endoscopist's approach to these patients.

Knowledge gaps identified will help guide future training ${ }^{24}$ and educational events. Reviewing Barrett's esophagitis, caring for the IBD patient, and staging colorectal cancer will be prioritized. Endoscopy up-skilling courses could be used to introduce and advance technical proficiency in skills such as using endoclips or argon plasma coagulators.

\section{Limitations}

Our main limitation is that the definitive number of Canadian FPs that routinely perform endoscopy is unknown. This is not surprising as currently there is no national credentialing body or certificate in added competence in gastroenterology for FPs. While 20 out of 29 (69\%) of Canadian family physician endoscopists attending a national primary care endoscopy $\mathrm{CE}$ event participated in the survey, whether the results are generalizable to those who did not participate or did not attend the $\mathrm{CE}$ event is unknown. However, the lead author has chaired a national CE event for FP endoscopists for the past 7 years, and estimates there are fewer than 40 Canadian FP endoscopists.

\section{Conclusion}

Canadian FP endoscopists report performing, and comfort with, basic endoscopic skills such as intubating the terminal ileum, while leaving advanced procedures like esophageal dilations or stenting to other endoscopists. FP endoscopists appear to be adhering to guideline recommendations such as using split bowel preparations, performing rectal retroflexion, and tattooing advanced lesions, all characteristics of a quality endoscopist or endoscopy programs. Future educational events will address identified knowledge gaps including care of IBD patients and staging rectal cancer.

ACKNOWLEDGMENTS: We would like to thank Drs Colm MacCarthy and Ryan Torrie for piloting early iterations of the survey, Sharon Nickel and Karyn Crawford for help with manuscript preparation, and Dr G. Michael Allan for reviewing the manuscript. Finally, we wish to thank all endoscopists who completed the survey.

CORRESPONDING AUTHOR: Address correspondence to Dr Kolber, 6-60 University Terrace, University of Alberta, Edmonton, Alberta, Canada T6G 2T4. 780-248-2057. Fax: 780-2482039.mkolber@ualberta.ca.

\section{References}

1. Hilsden RJ, Tepper J, Moayyedi P, Rabeneck L. Who provides gastrointestinal endoscopy in Canada? Can J Gastroenterol. 2007;21(12):843846. 
2. College of Family Physicians of Canada, Canadian Medical Association, Royal College of Physicians and Surgeons of Canada. National Physician Survey 2004. Procedures performed by family physicians, 2004. www.nationalphysiciansurvey.ca/nps/results/PDF-e/FP/Tables/National/Q8fp.pdf. Accessed December 10, 2007.

3. Kolber MR, Wong CKW, Fedorak RN, Rowe $\mathrm{BH}$; APC-Endo Study Physicians. Prospective Study of the Quality of Colonoscopies Performed by Primary Care Physicians: The Alberta Primary Care Endoscopy (APC-Endo) Study. PLoS One. 2013;8(6):e67017.

4. Kolber M, Szafran O, Suwal J, Diaz M. Outcomes of 1949 endoscopic procedures: performed by a Canadian rural family physician. Can Fam Physician. 2009;55(2):170-175.

5. Rabeneck L, Paszat LF, Saskin R. Endoscopist specialty is associated with incident colorectal cancer after a negative colonoscopy. Clin Gastroenterol Hepatol. 2010;8(3):275-279.

6. Bressler B, Paszat LF, Chen Z, Rothwell DM, Vinden C, Rabeneck L. Rates of new or missed colorectal cancers after colonoscopy and their risk factors: a population-based analysis. Gastroenterology. 2007;132(1):96-102.

7. Singh H, Nugent Z, Demers AA, Bernstein CN. Rate and predictors of early/missed colorectal cancers after colonoscopy in Manitoba: a population-based study. Am J Gastroenterol. 2010;105(12):2588-2596

8. Rex DK, Schoenfeld PS, Cohen J, et al. Quality indicators for colonoscopy. Gastrointest Endosc. 2015;81(1):31-53.

9. Chilton A, Rutter M, eds. Quality Assurance Guidelines for Colonoscopy NHS BCSP Publication No. 6. Sheffield, UK: NHS Cancer Screening Programmes; 2011.
10. Beshiri R, Bollman RD, Clemenson H. Definitions of "Rural". [pp. 21-601] Ottawa, Ontario: Statistics Canada, Agriculture Division; 2002.

11. Participants in the Paris Workshop. The Paris endoscopic classification of superficial neoplastic lesions: esophagus, stomach, and colon. Gastrointest Endosc. 2003;8(6):S3-S43.

12. Sharma P, Dent J, Armstrong D, et al. The development and validation of an endoscopic grading system for Barrett's esophagus: the Prague C \& M criteria. Gastroenterology. 2006;131(5):1392-1399.

13. Siegal D, Yudin J, Kaatz S, Douketis JD. Periprocedural heparin bridging in patients receiving vitamin $\mathrm{K}$ antagonists: systematic review and meta-analysis of bleeding and thromboembolic rates. Circulation. 2012; 126(13):16301639.

14. Allan GM, Shute R. Atrial Fibrillation Patients Needing Brief Interruptions in Warfarin Bridge or Not? www.acfp.ca/tools-for-practice. Accessed September 4, 2015.

15. Douketis JD, Spyropoulos AC, Kaatz S, et al; BRIDGE Investigators. Perioperative Bridging Anticoagulation in Patients with Atrial Fibrillation. N Engl J Med. 2015;373(9):823-833.

16. Tanguay JF, Bell AD, Ackman ML, et al; Canadian Cardiovascular Society. Focused 2012 update of the Canadian Cardiovascular Society guidelines for the use of antiplatelet therapy. Can J Cardiol. 2013;29(11):1334-1345.

17. Vandvik PO, Lincoff AM, Gore JM et al. Primary and Secondary Prevention of Cardiovascular Disease Antithrombotic Therapy and Prevention of Thrombosis, 9th ed: American College of Chest Physicians Evidence-Based Clinical Practice Guidelines. Chest. 2012; 141(2)(Suppl):e637S-e668S.
18. MacIntosh D, Dubé C, Hollingworth R, Veldhuyzen van Zanten S, Daniels S, Ghattas G. The endoscopy Global Rating Scale-Canada: development and implementation of a quality improvement tool. Can J Gastroenterol. 2013;27(2):74-82.

19. Singh M, Gupta N, Gaddam S, et al. Practice patterns among U.S. gastroenterologists regarding endoscopic management of Barrett's esophagus. Gastrointest Endosc. 2013;78(5):689-695.

20. Kanakadandi V, Parasa S, Sihn P, et al. Patterns of antiplatelet agent use in the US. Endosc Int Open. 2015;3(3):E173-E178.

21. Robbins R, Tian C, Singal A, Agrawal D. Periprocedural management of aspirin during colonoscopy: a survey of practice patterns in the United States. Gastrointest Endosc 2015;-:1-6.

22. Lee SY, Tang SJ, Rockey DC, et al; Korean Association for the Study of Intestinal Disease. Managing anticoagulation and antiplatelet medications in GI endoscopy: a survey comparing the East and the West. Gastrointest Endosc. 2008;67(7):1076-1081.

23. Spencer FA, Prasad M, Vandvik PO, Chetan D, Zhou Q, Guyatt G. Longer- Versus ShorterDuration Dual-Antiplatelet Therapy After Drug-Eluting Stent Placement: A Systematic Review and Meta-analysis. Ann Intern Med. 2015;163(2):118-126

24. Walker T, Deutchman M, Ingram B, Walker E, Westfall JM. Endoscopy training in primary care: innovative training program to increase access to endoscopy in primary care. Fam Med. 2012;44(3):171-177. 